\title{
Chemical weathering of a granite stone sample from the Peruvudaiyaar Koil, Thanjavur, Tamil Nadu, India
}

\author{
R. Anu Padma ${ }^{1}$, R. Ramasamy ${ }^{2}$ and M.S. Mathews ${ }^{1}$ \\ ${ }^{1}$ Department Civil Engineering, Indian Institute of Technology Madras, Chennai, Tamil Nadu, India \\ ${ }^{2}$ (Department of Ocean Engineering Indian Institute of Technology Madras, Chennai, Tamil Nadu, India)
}

\begin{abstract}
A stone piece from a granite patina of Peruvudaiyaar (Brihadisvara) Temple, Thanjavur is taken and examined its chemical weathering features on its outer surfaces directly under EDAX attached Scanning Electron Microscope. Three grains of feldspars are identified in the piece of granite stone and 29 points were selected on outer surfaces of these 3 grains of feldspar. The analyses were calculated on the basis of $32(O)$ ions to study the intensity of insitu weathering of the grains of feldspar. The EDAX analyses show that grain I and II were subjected to extensive leaching of removal weathered products of alumina (kaolinite) and carbonates (bicarbonates and carbonates) with residual enrichment of silica. This feature is due to direct exposure of the feldspar grain surfaces to differential weathering by direct alternate attack of sunlight and rainfall over a period of one thousand years. On the other hand grain III was subjected to extensive chemical weathering leading to precipitation of kaolinite and carbonate at the expense of silica by slow infiltration of rainwater during this period. The grain III associated with cavity is located at the shadow region of rainfall attack in the granite patina stone piece. Coatings of corrosive resistant paintings may preserve and protect the structure to a certain extent.
\end{abstract}

Keywords: Brahadeeswarar Temple, Chemical weathering, Feldspar, Granite patina, Peruvudaiyaar Temple, Thanjavur

\section{Introduction}

The Peruvudaiyaar Koil is known as Sri Brahadeeswarar Temple is located in Tanjavur, the capital city of ancient Cholas' Kingdom, Tamil Nadu, and India. The temple is built by the Great Chola-King Raja Raja I in the $10^{\text {th }}$ Century AD, is an outstanding example of Cholas' Architecture. The apex of the tower (Photograph 1a) is the octagonal single stone granite piece of 81.25 tons [1]. The temple was constructed by granitic rocks. The decay of granite has been well known to architects and conservators of historical temples, buildings and monuments since the days of early civilization. The objectives of this article is to describe the total impacts of weathering agents on an granite stone sample after the construction of a temple which was constructed by chiseled granite stones exposing fresh outer surfaces. The common constituents in granite are alkali-feldspar and quartz which are very inert to chemical weathering under ordinary physical environment over a period of time $[2,3]$. The intensity of chemical weathering of feldspar affects only a few micron thicknesses from its outer surface during the period of several hundreds of year's duration. An attempt was made to study on the impacts of physical environment of the weathering processes over the geochemical compositional variations of feldspars due to weathering.

\section{Climatic Condition}

The temple is located in an alluvial plain of Cauvery Delta. The nearest coastline is located about 80 $\mathrm{km}$ from Thanjavur. However, the present climatic condition may be extrapolated to the past one thousand years. Weathering index is modified to suit the weathering of feldspar grains, the predominant mineral in granite.

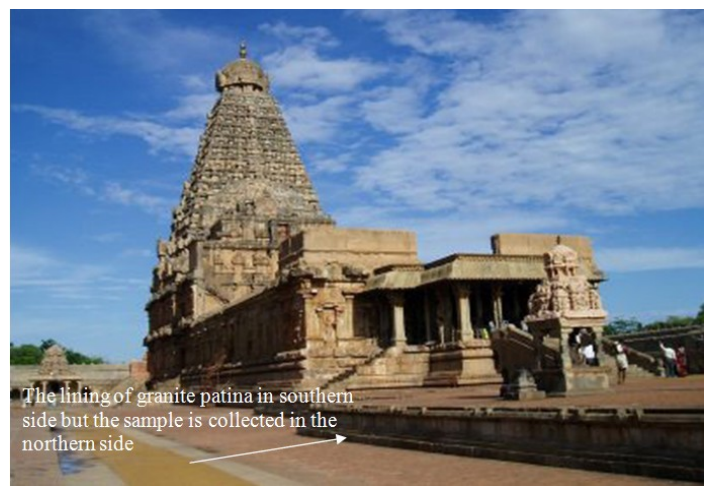


Photograph 1a shows the view of the Peruvudaiyaar Koil, Thanjavur, Tamil Nadu, and India. The ranite patina is seen in the temple at the basement. It exhibits weathering in association with development of scale along shear joints.

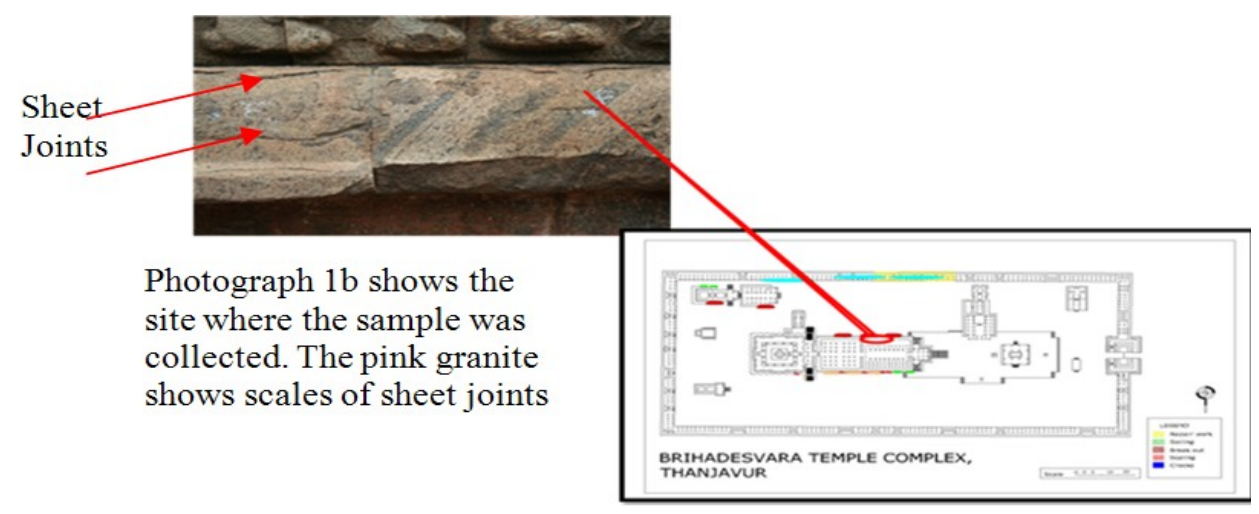

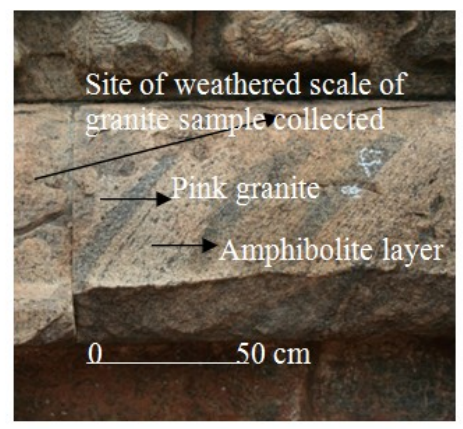

The photograph 2 Pink-granite patina showing parallel bands of grey amphibolite layers along foliation planes

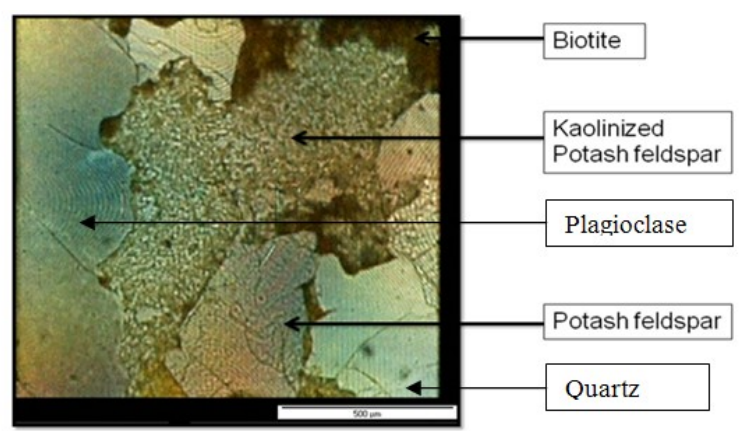

Photomicrograph 3 showing a granite rock with holocrystalline hypidiomorphic granular texture with potash feldspar, plagioclase and quartz (cross nicols).

The prevailing weathering condition is hot and dry tropical weathering. The location of the temple is $10^{\circ} 46^{\prime} 57.52 \mathrm{~N}-79^{\circ} 07^{\prime} 52.69^{\prime}$ 'E. Groundwater table lies $5 \mathrm{~m}$ below ground level which is $40 \mathrm{~m}$ above mean sea level (msl). The annual rainfall is below $1000 \mathrm{~mm}$. The land surface is covered with younger alluvial soil composed of over $70 \%$ of silt particles. The mean annual temperature is $29^{\circ} \mathrm{C}$. It is a flat deltaic terrain with 10 $50 \mathrm{~m}$ elevation above msl. In Thanjavur no coal based industries polluting atmosphere with $\mathrm{CO}_{2}$, and $\mathrm{SO}_{2}$ are seen. Therefore no significant production of gypsum or kaolinite by atmospheric action in rainwater by these $\mathrm{CO}_{2}$ and $\mathrm{SO}_{2}$ emissions in a short period is identified [4] The Cauvery River flows just south of the temple about $10 \mathrm{~m}$ from the outer wall of the temple and about $130 \mathrm{~m}$ from the centre of the temple sanctum. Thanjavur is the $11^{\text {th }}$ largest city in Tamil Nadu and its population is 221,190 according to the Census 2001. The Great Living Chola-Temple is an UNESCO World Heritage Monument. Nearest sea port is Nagapattinum located at $84 \mathrm{~km}$ east from Thanjavur. Prolonged periods of such climatic conditions may lead to spheroidal weathering of granite bodies comprising with strike, dip, oblique and sheet joints. Due to tropical differential weathering granite blocks separated by joints are formed as boulders which latter subjected to exfoliation with peeling of thin shells at the outer portion, leaving a hard and compact fresh spherical core portion. Granite bodies of horizontal outcrops and granite bodies covered with soils of 1 or $2 \mathrm{~m}$ thick, often subjected to development of horizontal sheet joints, probably due to differential weathering and release of overburden.

\section{Selection of Sample}

A broken piece of weathered scale of a pink granite patina from the Peruvudaiyaar Koil, Thanjavur was collected and selected to study the impacts of weathering processes acted during the course of past one thousand years after the construction of the temple. The broken very small piece of projected outer skin scale of the pink granite plate-let was subjected for this study. The exposed portion is subjected to sheet jointing and peeled off from the main rock. Below the weathered granite skin, the bottom portion of the granite appears to be very fresh. Owing to available accessibilities, only one sample was obtained for this study from the temple authorities. The sample was collected from a broken piece of a granite patina which located at the northern wall of the main temple. The granite patina was laid in the construction perpendicular to the ground surface at plinth level (Fig. 1b). The pink-granite sample is essentially composed of alkali feldspars and quartz with accessory minerals of biotite, magnetite and hornblende. Thin bands of grey coloured amphibolite layers mainly composed 
of hornblende and biotite are oriented along the foliation planes of the pink granite are seen. A few chips were cut for preparation of thin sections for megascopic, mineralogical and petrographical examinations. The granite sample was generally attacked by the weathering agencies like wind, rainfall, atmospheric pressure and temperature prevailed during the past one thousand years. More importance was paid to study the outer surface of the altered granite sample by observing the presence of thin films and coating over the granite sample. The granite sample is predominantly composed of feldspar grains over $60 \%$. Hence study of weathering of feldspar grains was focused. The weathering of feldspar is very similar to rusting of cast iron with development of patches and films of iron oxides on its surfaces. By megascopic examinations, it is known that the outer surface of the sample was subjected to alteration by different degree of weathering intensity from place to place and grain to grain and even point to point of a single grain on its outer surface. Unpolished raw feldspar grains for electron microprobe analyses were selected by observing their sizes, shapes, crystal morphologies, orientations, close to micro cavities and altered patches over the grain.

\section{Methodology}

The engineering properties of porosity and permeability of the rock materials were determined in the Civil Engineering Laboratory at Indian Institute of Technology Madras. Megascopic examination of physical characteristics of the granites sample was carried out. Thin section of the granite sample was cut and doubly polished with a standard thickness of $0.03 \mathrm{~mm}$ and pasted on a glass plate using Canada-balsam with a coverglass and studied under polarizing microscope passing polished light through the thin sections through lower nicol prism at varying magnifications. The mineral grains are also examined under upper cross nicol positioned $90^{\circ}$ to the lower nicol settings in the microscope above the thin section. Outer weathered surface of unpolished flat sample $\left(5 \times 4 \times 3 \mathrm{~mm}^{3}\right)$ was studied directly under scanning electron microscope Micronsperpixy-0031 attached with EDAX probe analyzer in the Metallurgical Laboratory of Indian Institute of Technology, Madras.

The scope of scanning electron microscope study is to investigate the outer morphology of weathered feldspar grains and to find out the intensity of weathering process affected the feldspar grains in the rock. Preparing a flat surface at the bottom, the rock sample is fixed with glue sticker paper on an inert disc with $0.00^{\circ}$ tilt. Feldspar grain was selected by observing crystal structure of the mineral grains. Outer surfaces of the weathered skins of feldspar grains under the scanning electron microscope at varying magnifications under Micronsperpixy 0031 attached with EDAX microprobe analyzer were examined. Back scattering images were taken for mineral phase analyzes and identifications. Based on crystal morphological characteristics of feldspars, outer surfaces of three grains were chosen for microprobe analyses. The probe analyses were carried out on length and breadth of feldspar grains to study the systematic geochemical weathering pattern on the outer surface of the grains. In the first grain 7 analyses were carried out in longitudinal direction and in the second and third grains 5 analyses were carried out in longitudinal directions. Width wise 4 analyses were carried out in all the three grains on either sides of the central point (Plates I, II, III and Table 1, 2 and 3). In order to reduce anomalies in chemical elemental variations, only selected elements commonly present in feldspars, namely, $\mathrm{O}$, $\mathrm{Si}, \mathrm{Al}, \mathrm{Fe}, \mathrm{Ca}, \mathrm{Na}, \mathrm{K}$ are analyzed. The elemental analyses were recalculated to their oxide proportions. Based on oxide (number of elemental ions in wt. \%) proportions cations [5] and anions on the basis of volume proportions in structural formula of $32(\mathrm{O})$ for feldspar [6] were calculated. Anion calculation is useful to study the replacement of one mineral by another by exchange of one anion of a particular element by one anion of other element without any volume changes [7]. Such calculation is also explains order-disorder relationships of feldspar and its structural coordination. Fresh feldspar do not exceed or deficient over 0.5 anions from its standard structural site.

In order to study, impact of weathering processes on feldspars both chemical leaching and new mineral formation are taken into account. A new chemical weathering index for feldspathic component is proposed after careful reviewing the formulae proposed for chemical weathering indices for rocks and soil materials $[8,9,10$, 11]. The intensity of weathering depends on the mobility and immobility of the major ion present in the rock / mineral. In feldspars the mobile anions are $\mathrm{Si}, \mathrm{Na}, \mathrm{K}$ and $\mathrm{Ca}$ and the immobile ions are $\mathrm{Al}$ and Fe. The chemical leaching index (CLI) is proposed by using the differences between total volumetric concentration of mobile ions in fresh feldspar grain as per formulae unit is 16 (i.e. 12 for tetrahedral site $\mathrm{Si}^{\mathrm{iv}} \& \mathrm{Al}^{\mathrm{iv}}$ ) and 4 for octahedral site $(\mathrm{Ca}, \mathrm{Na}, \mathrm{K})$. Thus total volumetric concentration of mobile ions in analyzed weathered spots is 16 . The chemical leaching index is defined as

$$
\begin{array}{lc}
C L I=\left(100\left(A_{\text {mobile }}-B_{\text {mobile }}\right)\right) / A_{\text {mobile }} & (\text { Ceryon, 2007) } 10 \\
C L I=\left(100\left(16-B_{\text {mobile }}\right)\right) / 16 & \text { where, }
\end{array}
$$

$\mathrm{A}_{\text {mobile }}=\mathrm{Si}, \mathrm{K}, \mathrm{Na}, \mathrm{Ca}$ in unaltered rock (Ceryon 2007) $10=$ unaltered feldspar standard formula unit $=16$

$\mathrm{B}_{\text {mobile }}=\mathrm{Si}, \mathrm{K}, \mathrm{Na}, \mathrm{Ca}$ in weathered rock (Ceryon 2007) 10= outer surface of weathered feldspar ions.

Here instead of taking rock, feldspar mineral is considered in the place of rock. $\mathrm{Al}^{\mathrm{vi}}$ and $\mathrm{Fe}^{\text {"” }}$ are less affected by chemical leaching than alkalis and alkaline earth elements. They tend to concentrate in weathering products as immobile ions. If drainage is well developed, mobile anions move away, if not they tend to concentrate in 
weathering products. The ratio of the total amount of these oxides in the weathering product to those in the fresh sample yields the amount of weathering products. Therefore, the chemical weathering product index (CWPI) is defined through the following equation:

$$
\begin{aligned}
& \mathrm{CWPI}=\left(100\left(\mathrm{~B}_{\text {immobile }}-\mathrm{C}_{\text {immobile }}\right)\right) / \text { Bimmobile } \\
& \mathrm{CWPI}=\left(100\left(\mathrm{~B}_{\text {immobile }}-4\right)\right) / \mathrm{B}_{\text {immobile }} \quad \text { where }
\end{aligned}
$$

$B_{\text {immobile }}=$ total volumetric concentration of immobile anions in weathered material

$\mathrm{C}_{\text {immobile }}=$ total volumetric concentration of immobile anions in standard feldspar unit $=4$

4 ions represent for hexahedral coordination $\left(\mathrm{Al}^{\mathrm{vi}}, \mathrm{Fe}\right.$ "') formulae unit of fresh feldspar.

Total Chemical Weathering Index (TCWI) can be calculated using the following formula

$\mathrm{TCWI}=(\mathrm{CWPI}+\mathrm{CLI}) / 2$. Highly weathered feldspar has higher degree of TCWI. The negative values

of CLI, CWPI and TCWI indicate that even the outer surfaces of feldspar grains are subjected very limited decay by differential weathering over the period of one thousand years after the construction of the temple.

Using, analyzed weathered material formed at the outer skin of feldspar grain, an attempt is made to recalculate normative feldspar proportions on the basis of cations of Rittmann's norm [5]. Required alkalis, alkaline earth $(\mathrm{Ca})$ and silica cations are utilized for normative proportion of residual feldspars. All iron cations are considered to be ferric iron and allotted for anorthite feldspar proportions in the place of alumina. After allotting normative proportions of feldspar constituents, excessive cations of $\mathrm{Si}, \mathrm{Al}, \mathrm{Ca}, \mathrm{Na}$, and $\mathrm{K}$ are treated as the chemical composition of weathered materials derived from in situ weathering of feldspar grain. Rittmann's normative calculation of stable igneous mineral assemblages in weathered materials gives co-existing mineral phases of potash feldspars and plagioclases consisting of varying proportions of or, ab and an proportions in feldspars. Assumed that the normative proportion of feldspars calculated represents the mineralogical composition of residual feldspar and the mobile $(\mathrm{Si}, \mathrm{Ca}, \mathrm{Na}, \mathrm{K})$ and immobile (Al) cations (iron as treated as ferric iron and added to Al cations to calculate anorthite cations) and the excessive cations remained after calculation of normative feldspar component are treated as weathered products of quartz, kaolinite and carbonates. Thus

$C L I=\left(100 *\left(\left(\right.\right.\right.$ or*0.8) $\left.\left.+(\mathrm{ab} * 0.8)+(\mathrm{an} * 0.6)-\mathrm{R}_{\mathrm{Si}}+\mathrm{R}_{\mathrm{Ca}}+\mathrm{R}_{\mathrm{Na}}+\mathrm{R}_{\mathrm{K}}\right)\right) /(($ or*0.8) $+(\mathrm{ab} * 0.8)+(\mathrm{an} * 0.6))$

$C W P I=100 *=\left(100 *\left(\mathrm{R}_{\mathrm{Al}}-((0.2 *\right.\right.$ or $)+(0.2 * \mathrm{ab})+(0.4 *$ an $\left.))\right) / \mathrm{R}_{\mathrm{Al}}$ where $\mathrm{R}=$ residual ions

$T C W I=(C W P I+C L I) / 2$.

$\mathrm{R}_{\mathrm{Al}}$ approaches to 0. CWPI is assumed to be a maximum value of -999 . The site exposed to differential weathering (core-centre portion) have higher degree of $C L I, C W P I$ and $T C W I$. Omitting normative proportions of feldspars from the compositions of the weathered material (outer surface of grains of feldspar investigated) residual cations of mobile and immobile cations were calculated. If the residual cations were derived from weathering of original feldspar, the losses of cations proportion were recalculated, assuming that they were lost by chemical leaching of feldspar. Then the difference between the normative proportion of feldspar components calculated and the cations lost were determined and again the distribution of mobile and immobile cations were calculated by further refining the data (Table 1, 2, 3). From bulk composition of analyzed weathered material, it is necessary to subtract feldspathic cations to estimate residual cations left out in the weathered product. Similarly residual Al" and $\mathrm{Ca}+\mathrm{Na}+\mathrm{K}$ " are calculated by subtracting necessary cations from the bulk composition of weathered materials.

\section{Petrographical Investigations}

\section{Experimental Analysis}

The rock sample is pink in colour. The colour is mainly due to presence of pink coloured feldspar grains. The granite is inter-layered with alternate bands and layers of amphibolites mainly composed of hornblende and biotite. It is a hard and compact medium grained to coarse-grained holocrystalline rock with glistening grains of vitreous quartz and feldspar with specks of dark green biotite, hornblende and magnetite.

The rock exhibits interlocking mosaic grains of quartz and feldspar. Both bluish green and yellowish biotite and hornblende are seen. In places orthoclase is subjected to deuteric alteration with dispersion of small flakes of sericite in orthoclase. Thin sections show cross sections of fresh mineral grains without any symptoms of weathering features. No secondary minerals formed by weathering alterations are seen in thin sections.

However, features of kaolinization and sericitization of feldspar are seen in some parts of thin sections of the rock. This feature of kaolinization appears to be primary alteration formed during the course of deuteric or metasomatic alteration by hydrothermal processes and not by weathering actions. Thin section studies under polarizing microscope; it is possible to distinguish precipitated films and patches of secondary minerals without any specific crystalline features from the well crystallized secondary minerals formed by post-magmatic changes. The secondary minerals formed by post magmatic processes are always much older than the minerals precipitated by chemical weathering, since the latter exhibits depositional film or precipitated aggregates.

During thin section preparation such features are totally removed off. The rock exhibits hypidiomorphic granular texture with interstitial grains of quartz amidst feldspar grains without any symptoms 
of presence of weathered products. The rock is composed of quartz $35 \%$, sodic oligoclase $28 \%$, orthoclase $24 \%$, microcline $10 \%$, biotite $1 \%$, hornblende $1 \%$, magnetite $0.5 \%$, pyroxene and other accessory mineral is of $0.5 \%$ in volume proportion.

\section{Mineralogical Investigations}

Thin sections of the rock show that most mineral grains appear to be very fresh and little altered by weathering. However incipient marginal zoning is found around oligoclase. Both perthite with blebs of sodicoligoclase $\left(\mathrm{An}_{8}{ }^{-} \mathrm{An}_{12}\right)$ and microcline with gridiron twinning are seen. The shape of feldspar grains varies from lath / prism shaped to subhedral grains. Both feldspars and quartz grains appear to be almost equigranular with intersertal mosaic texture. The size of feldspar and quartz grains widely varies from less than $1 \mathrm{~mm}$ to $3 \mathrm{~mm}$ dimension. The ratio of length and breadth of feldspar and quartz grains varies from 8:1 to 1:1. Quartz shows primary alterations with development of irregular and corroded outline in places and these features are due reaction of quartz with residual magmatic liquids during its growth. This feature does not represent any symptom of weathering action. Compositions of potash feldspars vary from or ${ }_{40} \mathrm{or}_{100} \mathrm{and}^{\mathrm{an}} \mathrm{n}^{-} \mathrm{an}_{46}$. The rock belongs to granite with significant amount of quartz in equal volume proportions of plagioclase and potash feldspars. Biotite and sericite are present as significant accessory minerals. Hornblende and magnetite are other accessory minerals present in the rock. Potash feldspar / perthite showing one or two blebs or lamellae of albite to sodic-oligoclase $\left(\mathrm{an}_{8}-\mathrm{an}_{12}\right)$ is the predominant mineral found in the rock. Microcline showing gridiron twinning is also found. Oligoclases showing polysynthetic twinning are rarely seen. Their anorthite content ranges from albite to rarely calcic oligoclase $\left(\mathrm{Ab}_{100} \mathrm{An}_{0}-\mathrm{Ab}_{64} \mathrm{An}_{36}\right)$. Some potash feldspars show relics of twinning lamellae of oligoclase indicating the rock was subjected to post-magmatic potash metasomatism due to formation of potash feldspar replacing oligoclase and its twinning lamellae. Kaolinite formed by deuteric alteration of potash feldspar is also seen. Thin plates of kaolinite and fine flakes of sericite are distributed along the cleavage planes of feldspars. Though potash metasomatism, deuteric alteration and chemical weathering are similar processes that taking place by dissolution and re-precipitation but with relative solubility of the mineral phases in the fluid phase respectively of lowering of temperatures towards chemical weathering [12]. Chemical weathering at atmospheric conditions cannot produce high temperature sericite and kaolinite. Formation of fine flakes of sericite and thin plates of kaolinite indicate that they were formed at much higher temperature and fluid regime than that of chemical weathering conditions. According to Fitzner and Heinrich [13] chemical weathering state is restricted only to environmental conditions of atmospheric temperature and humidity over a period of a few hundred years.

\section{Scanning Electron Microscopic (SEM) Study}

Using SEM, the ratios of lengths $(32 \mu \mathrm{m} ; 93 \mu \mathrm{m}$, and $64 \mu \mathrm{m})$ and breadths $(4 \mu \mathrm{m}, 54 \mu \mathrm{m}, 18 \mu \mathrm{m}))$ of the feldspar grains respectively vary from the grain 1 to 2 and 3 respectively are 8:1, 2:1 and 7:2. However the thickness of the grain III is fairly stout in nature with steeply dipping edges on both sides. SEM examination reveals presence of films and patches at the outer margins of the grains or in the cavities found adjoining feldspar grains. Under higher magnifications, the feldspar grains appear to be euhedral or idiomorphic in form with well developed crystal faces. The grain I is euhedral cylindrical prism in shape. The cylindrical shape of the grain is revealed only by SEM examination. In polarizing microscope, it may appear to be a lath shaped feldspar with high length and breadth ratio. It is a contact twin with a twin plane (010) under Carlsbad law. The grain is branching out into two along a common twinning plane. The twinning plane seems to be subjected to alteration with development of staining. A number of micro-cavities are present at the contact of the cylindrical grain. The grain 2 appears with (010) form. At the top of the grain is subjected to gliding and alteration along a cleavage plane. The bottom portion is projected above the surface with a micro-cavity. A number of patches and staining are found on the surfaces of the grain II examined. Projections of interpenetrating twins are also found in the near top of (010) face. A number of patches and stains are seen over the grain 3. Peripheral micro-cavities are seen around the grain. The morphology of the three grains shows that they were rapidly crystallized from the magma under high temperature condition. SEM studies reveal that presence of micro-cracks of varying dimensions (less than $1 \mu \mathrm{m}$ to $22 \mu \mathrm{m}$ and shapes (triangular, prism shaped and cavernous) at the contact of feldspars. However most of them appear to be open and are limited to a depth of 2 to $5 \mu \mathrm{m}$. Though under higher magnification the rock appears to be porous in nature, the pores are not interconnected and are isolated. The permeability of the rock tested under atmospheric pressure and temperature, is 0 . The porosity determined at vacuum condition is $0.13 \%$. These engineering properties are well coincided with SEM observations. SEM observation reveals that the outer surface of the rock is irregular and very rough in nature. Under higher magnification, SEM reveals that presence of innumerable patches or staining on the surfaces of mineral grains studied. The mineral grains formed by weathering or staining of feldspars show euhedral forms but it is difficult to identify such altered minerals owing to their small sizes with measuring their optical properties. With limited crystal morphological features, unknown minerals cannot be identified. Using SEM optical properties of such 
fine minerals cannot be studied. Further the scope of the investigation is different. Alterations due to weathering are extensively seen along grain boundaries, close to micro cavities, cleavage planes, micro fractures at the contact plane / edges of two faces, twinning planes and at the exposure-places where the mineral directly oriented facing the direction towards the impacts of weathering agents. Staining is often found as patches and may be caused by surface tension phenomena encountered by hydrophilic and hydrophobic nature of mineral face subjected to alteration. Micro-cavities and pores play critical role on the wetting and dry condition during rain drops rolling down [14]

\section{Geochemical Variations}

The structural formulae (Table 1,2,3) calculated on the basis of 32(O), reveal that the compositions of weathered materials present on the surfaces of feldspars [6] greatly deviate more than 0.5 ions from normal structural formulae of original fresh feldspar compositions indicating that they are the mixtures different proportions of kaolinite, carbonates, silica and residual feldspars. The tetrahedral (Si) greatly excess over 12 in the analyses of weathered materials for the feldspar grains 1 and 2 and they are deficient for the weathered materials developed on the feldspar grain 3. The excess of tetrahedral site over 12 ions are due to enrichment of residual silica by release or dissolution of equivalent $\mathrm{Al}$ and $\mathrm{Ca}+\mathrm{Na}+\mathrm{K}$ ions. The enrichment of $\mathrm{Al}$ and $\mathrm{Ca}+\mathrm{Na}+\mathrm{K}$ in the grain 3 reveals that the weathered material is subjected to dissolution and removal of silica with equivalent precipitation of kaolinite and carbonates of calcium and alkalis. Ferromagnesian minerals like biotite, hornblende and magnetite are oxidized and coated as patches at some places of feldspar grains indicating early stages of oxidation and weathering. $\mathrm{Al}$ is greatly deficient in its six fold co-ordination and Fe could not compensate this deficiency to 4 as $\mathrm{Fe}$ ". Similarly, in octahedral site is also vacant due to insufficiency of $(\mathrm{Ca}+\mathrm{Na}+\mathrm{K})$ ions in grains I and II but they are abundant with Si deficiency in grain III. Hence, the analyzed portion of the feldspar component ideally deviates from the structural formulae of feldspars subjected to magmatic differentiation or metasomatic changes during the course of their geneses. Only weathering alterations should be caused for these deviations. The addition and subtraction diagram of anion proportion on the basis of $32(\mathrm{O})$ indicates dissolution and removal of $\mathrm{Al}$ and $\mathrm{Ca}+\mathrm{Na}+\mathrm{K}$ with accumulation of residual silica (quartz) is seen in grains I and II in contrast to grain III (Fig. 1a). A linear negative correlation is found between the distribution of $\mathrm{Si}$ versus $(\mathrm{Ca}+\mathrm{Na}+\mathrm{K})$. This indicates presence of significant amount of leaching effect on the feldspars during the course of weathering (Fig. $1 b$ ). The normative calculation reveals that presence of excessive $\mathrm{Si}$ ions in the weathered products grains I and II but Si is deficient in grain III. However, the weathered product of feldspar grain III, shows excessive cations of $\mathrm{Ca}, \mathrm{Na}$ and even $\mathrm{K}$ with significant reduction of anorthite cations in most weathered surfaces (Table 1,2,3). This feature indicates that the silica deficiency was entirely utilized for the formation of clay (kaolinite which requires lower quantity of silica- $\mathrm{SiO}_{2} 46 \%$ (than alkali feldspar $\mathrm{SiO}_{2} 68 \%$ ) in addition to formation of carbonates. An attempt is made to calculate the co-existing
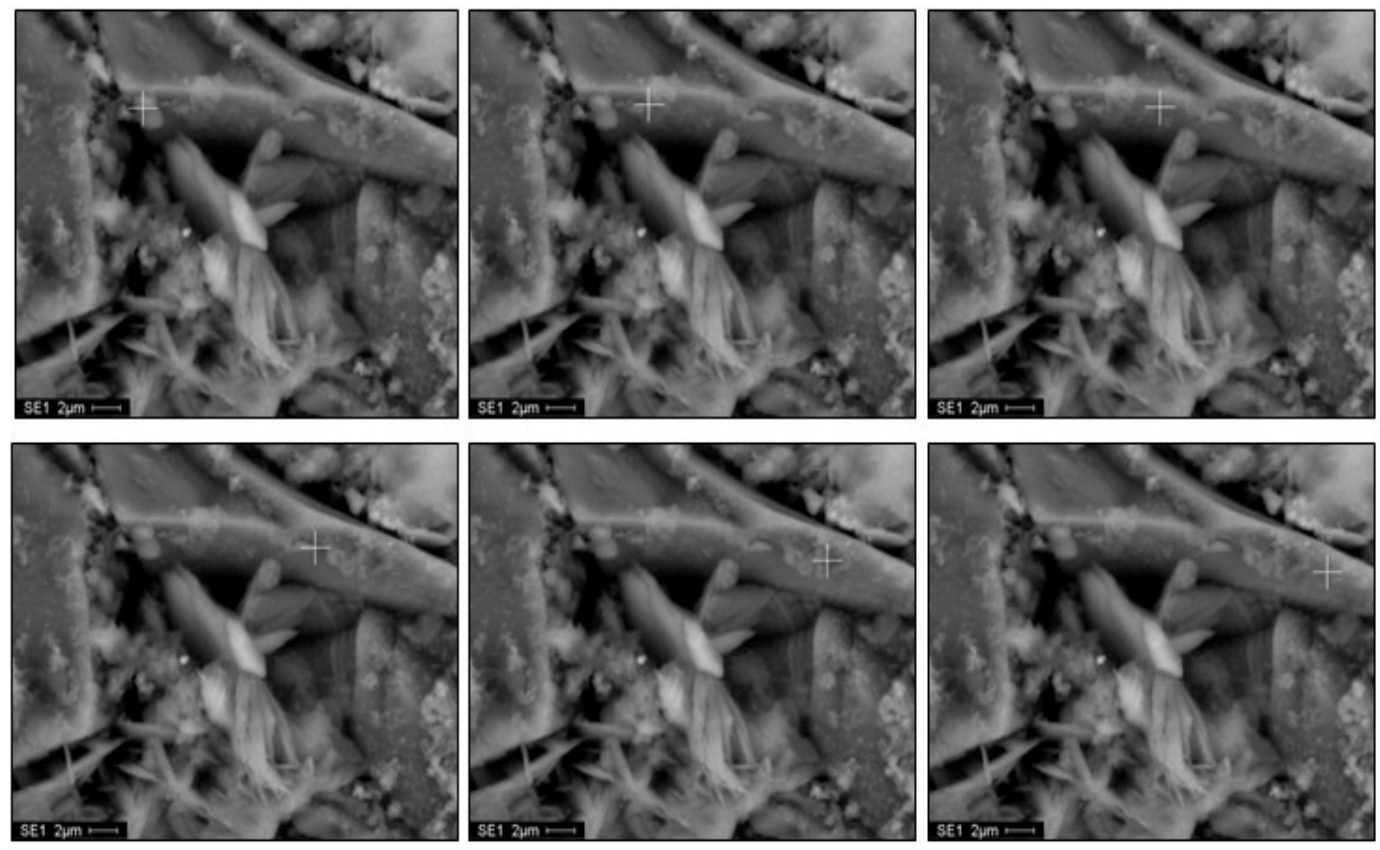

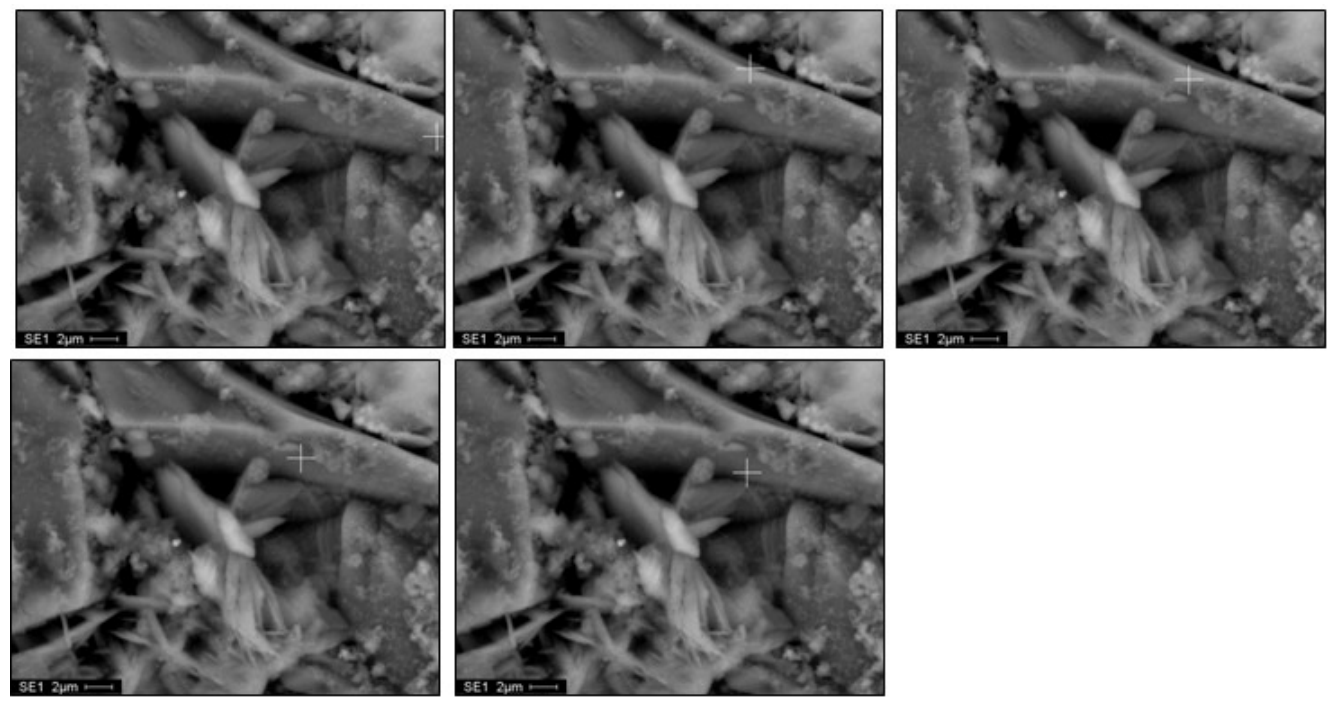

Plate I showing the presence of a cylindrical shaped twinned feldspar grain branched out at the top. The contact twinning plane is subjected to staining due to weathering. A number of triangular and linear microcavities are seen between various mineral grains. Under high magnification, lath shaped feldspars in polarizing microscope appear to be in cylindrical shape. They have high ratios of length and breadth in polarizing microscope. Branching is due to twinning of two individual grains growing together.

Normative proportion [5] of potash feldspar $(\mathrm{kfs} \%)$ and plagioclase $(\mathrm{an} \%)$, the results show that potash feldspar proportion increase with accommodation of more of albite constituents. On the other hand, anorthite content in plagioclase increases with expulsion of albitic constituents with decreasing proportion of plagioclase component (100-kfs\%). The grain II contains plagioclase of higher anorthite content (oligoclase to andesine) than the other two grains (ranging between albite and oligoclase). Andesine bearing granites are also common. Presence of excessive cations of $\mathrm{Si}, \mathrm{Ca}$ in the grain I and II and $\mathrm{Al}, \mathrm{Ca}, \mathrm{Na}$ and $\mathrm{K}$ in grain III indicates
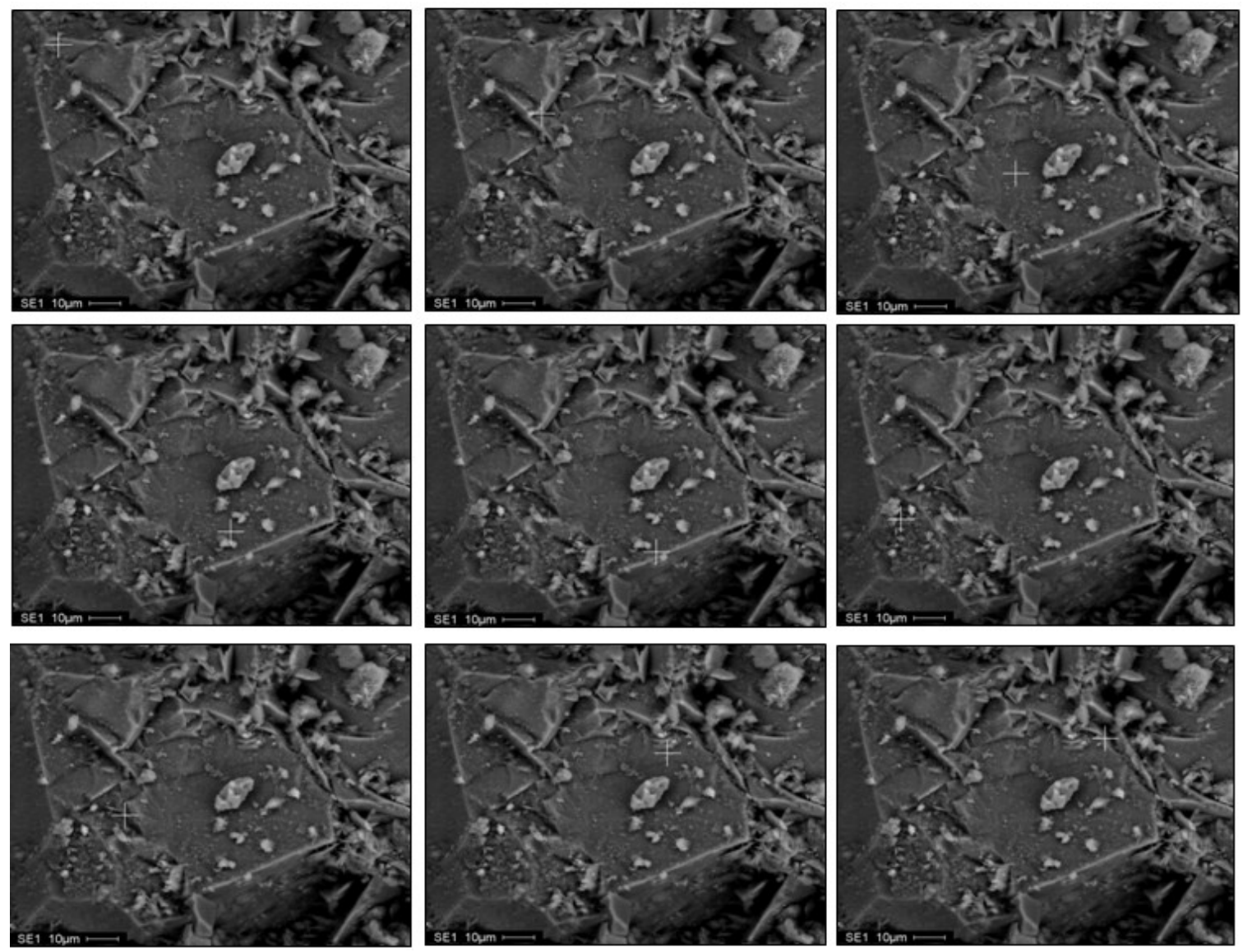
Plate II showing a potash feldspar grain with (010) crystal face. A cylindrical interpenetration twin of potash feldspar $(20 \mathrm{x}$ that the outer skin of the feldspar grains are affected by weathering processes. As the intensification of course of weathering, the differentiation trend moves towards lowering of plagioclase component with a steady decrease in anorthite content. The residual feldspar components vary from 36 to 0 with depletion of plagioclase component and increase of orthoclase content from 24 to 100 . The plagioclase thus released is converted to carbonates by weathering (Fig. 1c). Orthoclase and albite proportions are steadily increase during the course of extensive weathering (Fig. 1d). The Fig.1e shows that enrichment of residual quartz relative to residual carbonates in grains 1 and 2. On the other hand, dissolution of residual quartz with enrichment of residual carbonates is predominant in the grain III. The proportions of residual weathered materials against residual feldspars indicate, that the grains I and II are significantly enriched with feldspathic components. The degree of weathering is greater owing to abundance of weathered residual materials against feldspathic components in the grain III (Fig. 1f). Fig. $1 g$ and $1 h$ together indicate that the residual orthoclase component is greater in the grain III than in other feldspar grains. A linear negative correlation is seen with decreasing of residual Si against normative feldspar proportions (Fig. 1i). The Fig. $1 j$ ) reveals the zonal variation of cations in the grain I to III. Si and Al cations play a critical role in the chemical weathering of feldspathic components in the grain I and II and $\mathrm{Ca}+\mathrm{Na}+\mathrm{K}$ in the grain III. Close to cavity, negative indices are seen indicating depositional environment. Negative values are prominent in the second and third grains.
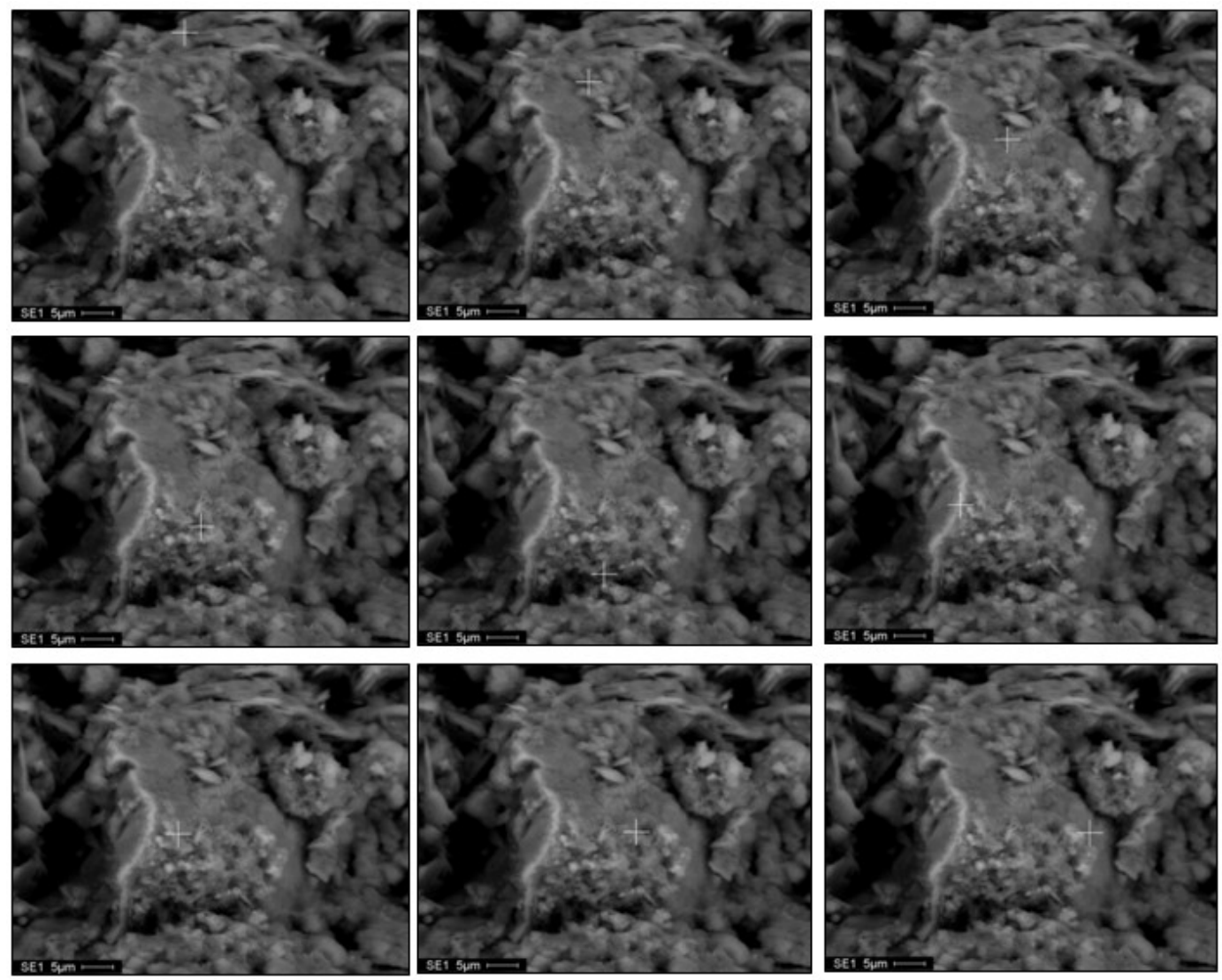

Plate III showing a highly corroded ad altered feldspar grain with a number of pits and cavities. Intergranular cavities raging in width from 10 to $15 \mu \mathrm{m}$ are seen. The peripheral cavity reveals that the feldspar grain is fairly stout in form with steep dipping towards the micro-cavity having a depth exceeding over $15 \mu \mathrm{m}$.

Chemical weathering product indices are highly negative in the grains I and in II but it is feebly positive in the grain III with accumulation of weathering products up to the index of $(0.21)$. Total weathering indices are negative for grain 1 (up to -242) and in grain II (up to -225) but grain III shows positive total weathering indices ranges up to -0.27 indicating that grain III is subjected to accumulation of weathered products. These features are illustrated in the Fig. $2 a$ and $2 b$. The negative values of chemical leaching indices, chemical weathering product indices and total weathering indices reveal the complete removal of the weathered materials either in solution or by mechanical transportations by rain water drops. However, the positive values indicate accumulation of weathered materials in patches over the surfaces of the mineral grains. Plot of these residual ions indicate a linear trend revealing that the weathered products are derived from weathering of feldspathic materials only (Table 1, 2, 3). Replacements of mobile elements are compensated with precipitation of immobile elements and vice versa. Thus losses of cations are equally compensated by addition of excessive 
cations. Hence residual $(\mathrm{Si} "+\mathrm{Ca} "+\mathrm{Na} "+\mathrm{K} "+\mathrm{Al} ")=0$, (Table 1, 2 and 3), assuming that final weathered materials on the outer surface of feldspar grains were derived by weathering of feldspars. All the three grains $(\mathrm{Si} "+\mathrm{Ca} "+\mathrm{Na} "+\mathrm{K} ")=-(\mathrm{Al}$ " $+\mathrm{Fe} ")$. This indicates that enrichment of mobile elements is possible at the expense of immobile elements.

Table 1 Eleven EDAX for Weathered Outer surface of a Feldspar grain I

\begin{tabular}{|c|c|c|c|c|c|c|c|c|c|c|c|}
\hline 1 & 2 & 3 & 4 & 5 & 6 & 7 & 8 & 9 & \multicolumn{2}{|c|}{10} & 11 \\
\hline $\mathrm{SiO} 2$ & 81.99 & 83.94 & 87.50 & 83.78 & 83.57 & 89.22 & 90.43 & 90.13 & 89.97 & 83.80 & 81.40 \\
\hline Al2O3 & 2.42 & 2.72 & 2.63 & 4.79 & 2.94 & 2.46 & 2.14 & 2.56 & 2.69 & 2.93 & 3.22 \\
\hline $\mathrm{FeO}$ & 0.76 & 0.74 & 0.78 & 1.02 & 0.76 & 0.52 & 0.89 & 0.49 & 0.46 & 0.91 & 1.37 \\
\hline $\mathrm{CaO}$ & 13.48 & 11.26 & 7.25 & 7.58 & 11.10 & 6.51 & 5.53 & 5.65 & 5.33 & 10.23 & 11.91 \\
\hline $\mathrm{Na} 2 \mathrm{O}$ & 0.29 & 0.24 & 0.70 & 0.86 & 0.69 & 0.43 & 0.12 & 0.64 & 0.61 & 0.78 & 0.87 \\
\hline K2O & 1.07 & 1.11 & 1.14 & 1.97 & 0.94 & 0.87 & 0.89 & 0.53 & 0.95 & 1.35 & 1.22 \\
\hline Total & 100.00 & 100.00 & 100.00 & 100.00 & 100.00 & 100.00 & 100.00 & 100.00 & 100.00 & 100.00 & 100.00 \\
\hline $32(0)$ & anions & & & & & & & & & & \\
\hline $\mathrm{Si}$ & 14.24 & 14.42 & 14.78 & 14.33 & 14.37 & 14.93 & 15.07 & 15.01 & 15.00 & 14.41 & 14.15 \\
\hline $\mathrm{Al}$ & 0.50 & 0.55 & 0.52 & 0.97 & 0.60 & 0.49 & 0.42 & 0.50 & 0.53 & 0.59 & 0.66 \\
\hline $\mathrm{Fe}$ & 0.15 & 0.15 & 0.16 & 0.20 & 0.15 & 0.11 & 0.19 & 0.10 & 0.10 & 0.18 & 0.27 \\
\hline $\mathrm{Ca}$ & 2.51 & 2.07 & 1.31 & 1.39 & 2.04 & 1.17 & 0.99 & 1.01 & 0.95 & 1.88 & 2.22 \\
\hline $\mathrm{Na}$ & 0.10 & 0.08 & 0.23 & 0.29 & 0.23 & 0.14 & 0.04 & 0.21 & 0.20 & 0.26 & 0.29 \\
\hline K & 0.24 & 0.24 & 0.25 & 0.43 & 0.21 & 0.19 & 0.19 & 0.11 & 0.20 & 0.30 & 0.27 \\
\hline CLI & -7 & -5 & -4 & -3 & -5 & -3 & -2 & -2 & -2 & -5 & -6 \\
\hline CWPI & -519 & -472 & -485 & -242 & -435 & -574 & -558 & -562 & -540 & -416 & -330 \\
\hline TCWI & -263 & -239 & -244 & -122 & -220 & -289 & -280 & -282 & -271 & -211 & -168 \\
\hline Cations & & & & & & & & & & & \\
\hline $\mathrm{Si}$ & 1364 & 1397 & 1456 & 1394 & 1391 & 1485 & 1505 & 1500 & 1497 & 1395 & 1355 \\
\hline $\mathrm{Al}$ & 47 & 53 & 52 & 94 & 58 & 48 & 42 & 50 & 53 & 57 & 63 \\
\hline $\mathrm{Fe}$ & 11 & 10 & 11 & 14 & 11 & 7 & 12 & 7 & 6 & 13 & 19 \\
\hline $\mathrm{Ca}$ & 240 & 201 & 129 & 135 & 198 & 116 & 99 & 101 & 95 & 182 & 212 \\
\hline $\mathrm{Na}$ & 9 & 8 & 23 & 28 & 22 & 14 & 4 & 21 & 20 & 25 & 28 \\
\hline $\mathrm{K}$ & 23 & 24 & 24 & 42 & 20 & 18 & 19 & 11 & 20 & 29 & 26 \\
\hline or & 113 & 118 & 121 & 209 & 100 & 92 & 95 & 57 & 101 & 143 & 130 \\
\hline$a b$ & 46 & 38 & 113 & 139 & 112 & 69 & 20 & 104 & 98 & 126 & 140 \\
\hline an & 66 & 81 & 39 & 96 & 65 & 58 & 79 & 62 & 48 & 40 & 71 \\
\hline Fels & 225 & 237 & 273 & 444 & 277 & 219 & 193 & 223 & 247 & 310 & 341 \\
\hline $\mathrm{Si}$ & 1243 & 1271 & 1300 & 1147 & 1237 & 1364 & 1405 & 1379 & 1358 & 1217 & 1164 \\
\hline $\mathrm{Al}$ & 0 & 0 & 0 & 0 & 0 & 0 & 0 & 0 & 0 & 0 & 0 \\
\hline $\mathrm{Ca}$ & 227 & 185 & 122 & 116 & 185 & 105 & 83 & 88 & 85 & 174 & 198 \\
\hline $\mathrm{Na}$ & 0 & 0 & 0 & 0 & 0 & 0 & 0 & 0 & 0 & 0 & 0 \\
\hline K & 0 & 0 & 0 & 0 & 0 & 0 & 0 & 0 & 0 & 0 & 0 \\
\hline or & 50 & 50 & 44 & 47 & 36 & 42 & 49 & 26 & 41 & 46 & 38 \\
\hline$a b$ & 21 & 16 & 41 & 31 & 41 & 32 & 10 & 47 & 40 & 41 & 41 \\
\hline an & 29 & 34 & 14 & 22 & 23 & 26 & 41 & 28 & 20 & 13 & 21 \\
\hline$k f s \%$ & 86 & 82 & 100 & 95 & 65 & 72 & 80 & 40 & 72 & 100 & 72 \\
\hline plan\% & 25 & 30 & 0 & 15 & 19 & 23 & 33 & 25 & 20 & 0 & 15 \\
\hline CLI & -782 & -739 & -574 & -276 & -582 & -796 & -972 & -786 & -667 & -480 & -427 \\
\hline CWPI & -999 & -999 & -999 & -999 & -999 & -999 & -999 & -999 & -999 & -999 & -999 \\
\hline TCWI & -890 & -869 & -787 & -637 & -791 & -897 & -986 & -892 & -833 & -740 & -713 \\
\hline or & 1043 & 1055 & 961 & 899 & 746 & 955 & 1146 & 586 & 926 & 939 & 740 \\
\hline$a b$ & 425 & 339 & 897 & 598 & 835 & 720 & 238 & 1070 & 895 & 824 & 796 \\
\hline an & 604 & 724 & 308 & 415 & 481 & 599 & 956 & 642 & 442 & 264 & 404 \\
\hline Si" & 121 & 145 & 62 & 83 & 96 & 120 & 191 & 128 & 88 & 53 & 81 \\
\hline Al" & -535 & -568 & -495 & -465 & -509 & -575 & -659 & -588 & -541 & -458 & -469 \\
\hline CaNaK" & 414 & 424 & 433 & 382 & 412 & 455 & 468 & 460 & 453 & 406 & 388 \\
\hline
\end{tabular}

Chemical Leaching Index (CLI), Chemical weathering product index (CWPI) and Total chemical weathering index (TCWI) are calculated on the basis of $32(\mathrm{O})$ ions presented in standard feldspar formula unit. On the other hand CLI, CWPI and TPWI are calculated on the basis of Rittmann's (1973) norm calculation for weathered material. The minimum chemical weathering product index $C W P I=-\infty$ and it is assumed to be limited to -999 cations and $T C W I=(C L I+C W P I) / 2$. The values of $C L I, C W P I$ and $T C W I$ indices together increase as the degrees of weathering increases and the difference between the values of indices reflect the amount of weathering experienced by the weathered material. Si", $A l$ " and CaNaK" represents residual cations in ultimate weathered materials i.e. $\mathrm{Si}-\mathrm{Si}{ }^{\prime}=\mathrm{Si} " ; \mathrm{Si}^{\prime}=\mathrm{Si}$ in or $+\mathrm{ab}+$ an of weathered product. 

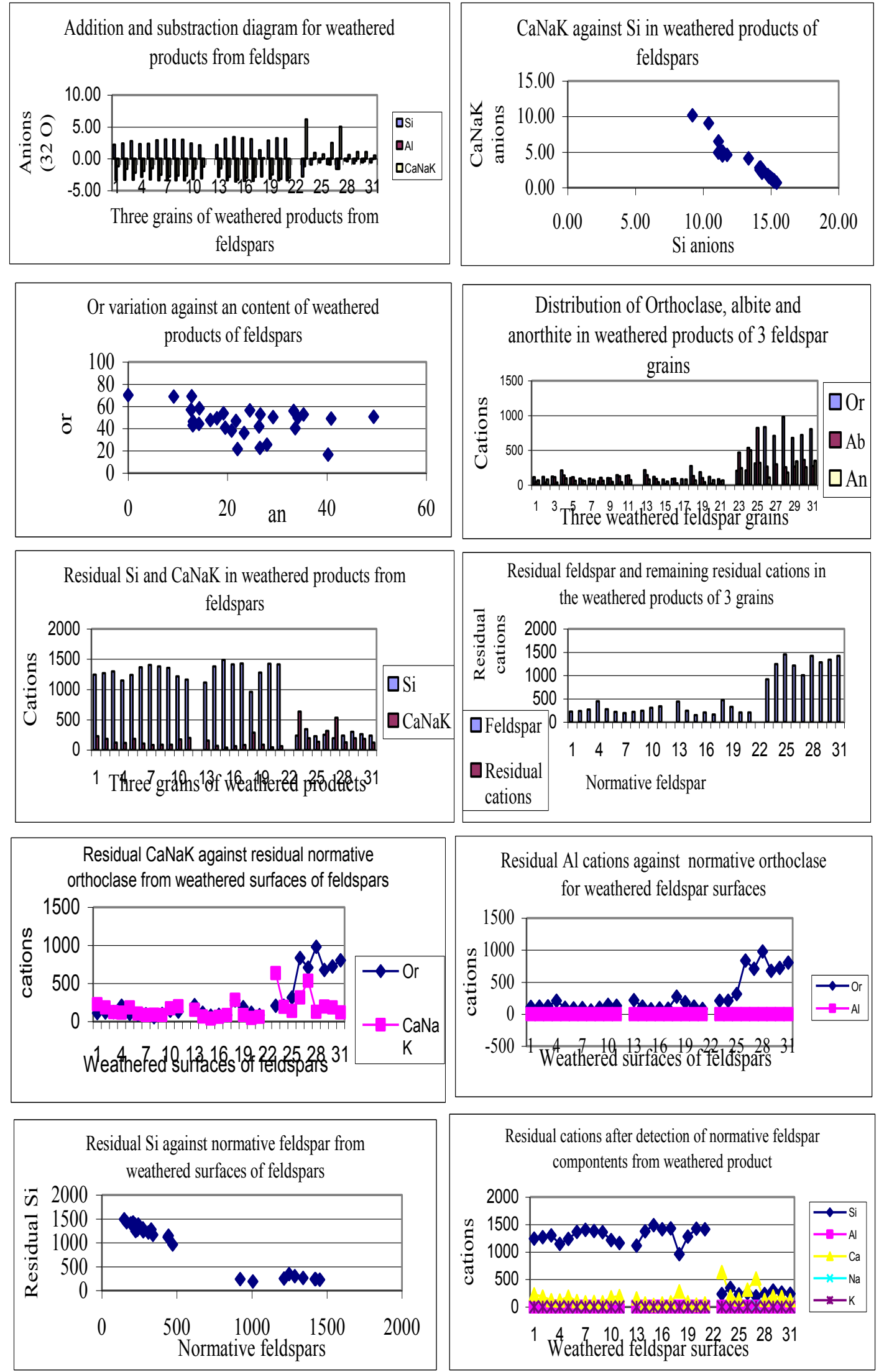

Fig. 1 a-J Variation diagrams (a-j) show chemical changes during the course of weathering of outer surface of feldspar grains exposed on the granite patina, Peruvudaiyaar Temple, Thanjavur, Tamil Nadu, India. 
Table 2. Nine EDAX for Weathered Outer surfaces of Feldspar grain II

\begin{tabular}{|c|c|c|c|c|c|c|c|c|c|}
\hline & 12 & 13 & 14 & 15 & 16 & 17 & 18 & 19 & 20 \\
\hline $\mathrm{SiO} 2$ & 81.90 & 91.11 & 94.14 & 92.24 & 90.92 & 73.96 & 88.20 & 92.40 & 91.64 \\
\hline Al2O3 & 4.22 & 2.33 & 1.68 & 1.92 & 2.07 & 4.33 & 3.01 & 2.37 & 2.35 \\
\hline $\mathrm{FeO}$ & 1.50 & 0.79 & 0.53 & 0.65 & 0.64 & 1.66 & 1.09 & 0.67 & 0.64 \\
\hline $\mathrm{CaO}$ & 9.45 & 4.15 & 2.80 & 3.77 & 5.59 & 16.66 & 5.31 & 3.32 & 4.25 \\
\hline $\mathrm{Na} 2 \mathrm{O}$ & 0.89 & 0.54 & 0.11 & 0.57 & 0.00 & 0.80 & 0.62 & 0.14 & 0.33 \\
\hline K2O & 2.04 & 1.09 & 0.74 & 0.84 & 0.79 & 2.59 & 1.76 & 1.10 & 0.78 \\
\hline Total & 100.00 & 100.00 & 100.00 & 100.00 & 100.00 & 100.00 & 100.00 & 100.00 & 100.00 \\
\hline \multicolumn{10}{|l|}{$32(0)$} \\
\hline $\mathrm{Si}$ & 14.18 & 15.13 & 15.43 & 15.25 & 15.11 & 13.35 & 14.85 & 15.25 & 15.17 \\
\hline Al & 0.86 & 0.46 & 0.32 & 0.38 & 0.41 & 0.92 & 0.60 & 0.46 & 0.46 \\
\hline $\mathrm{Fe}$ & 0.30 & 0.17 & 0.11 & 0.14 & 0.13 & 0.31 & 0.23 & 0.14 & 0.13 \\
\hline $\mathrm{Ca}$ & 1.75 & 0.74 & 0.49 & 0.67 & 1.00 & 3.22 & 0.96 & 0.59 & 0.75 \\
\hline $\mathrm{Na}$ & 0.30 & 0.17 & 0.04 & 0.18 & 0.00 & 0.28 & 0.20 & 0.05 & 0.11 \\
\hline K & 0.45 & 0.23 & 0.15 & 0.18 & 0.17 & 0.60 & 0.38 & 0.23 & 0.17 \\
\hline $\mathrm{CLI}$ & -4.29 & -1.73 & -0.68 & -1.73 & -1.72 & -9.08 & -2.45 & -0.68 & -1.20 \\
\hline CWPI & -245.63 & -543.33 & -814.00 & -678.06 & -641.46 & -225.12 & -385.89 & -562.45 & -573.51 \\
\hline TCWI & -124.96 & -272.53 & -407.34 & -339.90 & -321.59 & -117.10 & -194.17 & -281.56 & -287.36 \\
\hline \multicolumn{10}{|l|}{ Cations } \\
\hline $\mathrm{Si}$ & 1363 & 1516 & 1567 & 1535 & 1513 & 1231 & 1468 & 1538 & 1525 \\
\hline Al & 83 & 46 & 33 & 38 & 41 & 85 & 59 & 46 & 46 \\
\hline $\mathrm{Fe}$ & 21 & 11 & 7 & 9 & 9 & 23 & 15 & 9 & 9 \\
\hline $\mathrm{Ca}$ & 169 & 74 & 50 & 67 & 100 & 297 & 95 & 59 & 76 \\
\hline $\mathrm{Na}$ & 29 & 17 & 4 & 18 & 0 & 26 & 20 & 5 & 11 \\
\hline K & 43 & 23 & 16 & 18 & 17 & 55 & 37 & 23 & 17 \\
\hline or & 217 & 116 & 78 & 89 & 84 & 275 & 187 & 117 & 83 \\
\hline$a b$ & 144 & 87 & 18 & 91 & 0 & 129 & 100 & 23 & 54 \\
\hline an & 79 & 40 & 53 & 27 & 82 & 68 & 42 & 70 & 69 \\
\hline Fels & 439 & 243 & 149 & 207 & 165 & 472 & 329 & 209 & 206 \\
\hline $\mathrm{Si}$ & 1115 & 1378 & 1488 & 1416 & 1430 & 961 & 1278 & 1426 & 1415 \\
\hline Al & 0 & 0 & 0 & 0 & 0 & 0 & 0 & 0 & 0 \\
\hline $\mathrm{Ca}$ & 153 & 66 & 39 & 62 & 83 & 283 & 86 & 45 & 62 \\
\hline $\mathrm{Na}$ & 0 & 0 & 0 & 0 & 0 & 0 & 0 & 0 & 0 \\
\hline K & 0 & 0 & 0 & 0 & 0 & 0 & 0 & 0 & 0 \\
\hline or & 49 & 48 & 53 & 43 & 51 & 58 & 57 & 56 & 40 \\
\hline$a b$ & 33 & 36 & 12 & 44 & 0 & 27 & 30 & 11 & 26 \\
\hline$a n$ & 18 & 17 & 35 & 13 & 49 & 14 & 13 & 33 & 34 \\
\hline$k f s \%$ & 75 & 88 & 65 & 76 & 55 & 85 & 90 & 65 & 55 \\
\hline plan\% & 30 & 30 & 32 & 25 & 46 & 36 & 32 & 40 & 30 \\
\hline $\mathrm{CLI}$ & -277 & -675 & -1308 & -821 & -1204 & -241 & -435 & -858 & -879 \\
\hline CWPI & -999 & -999 & -999 & -999 & -999 & -999 & -999 & -999 & -999 \\
\hline TCWI & -638 & -837 & -1153 & -910 & -1102 & -620 & -717 & -928 & -939 \\
\hline or & 916 & 1098 & 1306 & 1014 & 1206 & 933 & 1212 & 1327 & 950 \\
\hline$a b$ & 610 & 819 & 298 & 1039 & 0 & 439 & 649 & 258 & 616 \\
\hline an & 332 & 380 & 875 & 307 & 1177 & 230 & 270 & 792 & 793 \\
\hline Si" & 66 & 76 & 175 & 61 & 235 & 46 & 54 & 158 & 159 \\
\hline Al" & -438 & -535 & -671 & -533 & -712 & -366 & -480 & -634 & -630 \\
\hline CaNaK" & 372 & 459 & 496 & 472 & 477 & 320 & 426 & 475 & 472 \\
\hline
\end{tabular}


Table 3. Nine EDAX for Weathered Outer surfaces of Feldspar grain III

\begin{tabular}{|c|c|c|c|c|c|c|c|c|c|}
\hline & 21 & 22 & 23 & 24 & 25 & 26 & 27 & 28 & 29 \\
\hline $\mathrm{SiO} 2$ & 44.53 & 59.70 & 62.26 & 57.51 & 50.87 & 63.21 & 60.14 & 61.01 & 61.46 \\
\hline Al2O3 & 10.98 & 15.96 & 17.16 & 12.48 & 8.26 & 15.35 & 15.35 & 15.05 & 16.82 \\
\hline $\mathrm{FeO}$ & 1.27 & 2.63 & 1.28 & 1.47 & 2.80 & 1.38 & 1.74 & 1.75 & 1.76 \\
\hline $\mathrm{CaO}$ & 38.36 & 16.41 & 11.26 & 19.01 & 29.04 & 9.23 & 14.74 & 13.15 & 10.69 \\
\hline $\mathrm{Na} 2 \mathrm{O}$ & 2.91 & 3.33 & 5.08 & 1.65 & 2.37 & 1.60 & 1.65 & 2.24 & 1.69 \\
\hline $\mathrm{K} 2 \mathrm{O}$ & 1.96 & 1.97 & 2.95 & 7.88 & 6.65 & 9.24 & 6.37 & 6.80 & 7.57 \\
\hline Total & 100.00 & 100.00 & 100.00 & 100.00 & 100.00 & 100.00 & 100.00 & 100.00 & 100.00 \\
\hline \multicolumn{10}{|l|}{$32(0)$} \\
\hline $\mathrm{Si}$ & 9.21 & 11.11 & 11.40 & 11.13 & 10.41 & 11.76 & 11.30 & 11.44 & 11.43 \\
\hline $\mathrm{Al}$ & 2.68 & 3.51 & 3.71 & 2.85 & 1.99 & 3.37 & 3.40 & 3.33 & 3.69 \\
\hline $\mathrm{Fe}$ & 0.16 & 0.41 & 0.20 & 0.23 & 0.41 & 0.23 & 0.27 & 0.28 & 0.28 \\
\hline $\mathrm{Ca}$ & 8.50 & 3.27 & 2.21 & 3.94 & 6.37 & 1.84 & 2.97 & 2.64 & 2.13 \\
\hline $\mathrm{Na}$ & 1.17 & 1.20 & 1.80 & 0.62 & 0.94 & 0.58 & 0.60 & 0.82 & 0.61 \\
\hline K & 0.52 & 0.47 & 0.69 & 1.95 & 1.74 & 2.19 & 1.53 & 1.63 & 1.80 \\
\hline $\mathrm{CLI}$ & -21.22 & -0.35 & -0.61 & -10.27 & -21.62 & -2.28 & -2.46 & -3.25 & 0.21 \\
\hline CWPI & -40.77 & -2.24 & -2.35 & -30.04 & -66.69 & -11.34 & -8.85 & -10.93 & -0.75 \\
\hline TCWI & -31.00 & -1.29 & -1.48 & -20.15 & -44.15 & -6.81 & -5.66 & -7.09 & -0.27 \\
\hline \multicolumn{10}{|l|}{ Cations } \\
\hline $\mathrm{Si}$ & 741 & 993 & 1036 & 957 & 847 & 1052 & 1001 & 1015 & 1023 \\
\hline $\mathrm{Al}$ & 215 & 313 & 337 & 245 & 162 & 301 & 301 & 295 & 330 \\
\hline $\mathrm{Fe}$ & 18 & 37 & 18 & 20 & 39 & 19 & 24 & 24 & 25 \\
\hline $\mathrm{Ca}$ & 684 & 293 & 201 & 339 & 518 & 165 & 263 & 234 & 191 \\
\hline $\mathrm{Na}$ & 94 & 107 & 164 & 53 & 77 & 51 & 53 & 72 & 54 \\
\hline K & 42 & 42 & 63 & 167 & 141 & 196 & 135 & 144 & 161 \\
\hline or & 208 & 209 & 314 & 836 & 706 & 981 & 677 & 722 & 804 \\
\hline$a b$ & 469 & 537 & 820 & 267 & 300 & 257 & 266 & 362 & 272 \\
\hline an & 244 & 502 & 320 & 111 & 0 & 182 & 342 & 257 & 349 \\
\hline Fels & 921 & 1247 & 1453 & 1215 & 1006 & 1420 & 1285 & 1341 & 1424 \\
\hline $\mathrm{Si}$ & 237 & 345 & 228 & 250 & 193 & 236 & 298 & 262 & 238 \\
\hline $\mathrm{Al}$ & 0 & 0 & 0 & 0 & 0 & 0 & 0 & 0 & 0 \\
\hline $\mathrm{Ca}$ & 635 & 192 & 137 & 317 & 518 & 128 & 194 & 183 & 121 \\
\hline $\mathrm{Na}$ & 0 & 0 & 0 & 0 & 17 & 0 & 0 & 0 & 0 \\
\hline K & 0 & 0 & 0 & 0 & 0 & 0 & 0 & 0 & 0 \\
\hline or & 23 & 17 & 22 & 69 & 70 & 69 & 53 & 54 & 56 \\
\hline$a b$ & 51 & 43 & 56 & 22 & 30 & 18 & 21 & 27 & 19 \\
\hline$a n$ & 27 & 40 & 22 & 9 & 0 & 13 & 27 & 19 & 24 \\
\hline$k f s \%$ & 18 & 10 & 22 & 92 & 100 & 85 & 65 & 76 & 75 \\
\hline plan\% & 35 & 50 & 32 & 65 & 0 & 65 & 75 & 60 & 66 \\
\hline $\mathrm{CLI}$ & -27 & 40 & 67 & 40 & 10 & 67 & 49 & 56 & 66 \\
\hline CWPI & -999 & -999 & -999 & -999 & -999 & -999 & -999 & -999 & -999 \\
\hline TCWI & -513 & -479 & -466 & -479 & -495 & -466 & -475 & -471 & -466 \\
\hline or & 89 & 96 & 82 & 287 & 226 & 272 & 262 & 235 & 224 \\
\hline$a b$ & 201 & 248 & 215 & 92 & 96 & 71 & 103 & 118 & 76 \\
\hline an & 105 & 232 & 84 & 38 & 0 & 50 & 132 & 84 & 97 \\
\hline Si" & 21 & 46 & 17 & 8 & 0 & 10 & 26 & 17 & 19 \\
\hline Al" & -100 & -161 & -93 & -91 & -65 & -89 & -126 & -104 & -99 \\
\hline CaNaK" & 79 & 115 & 76 & 83 & 64 & 79 & 99 & 87 & 79 \\
\hline
\end{tabular}



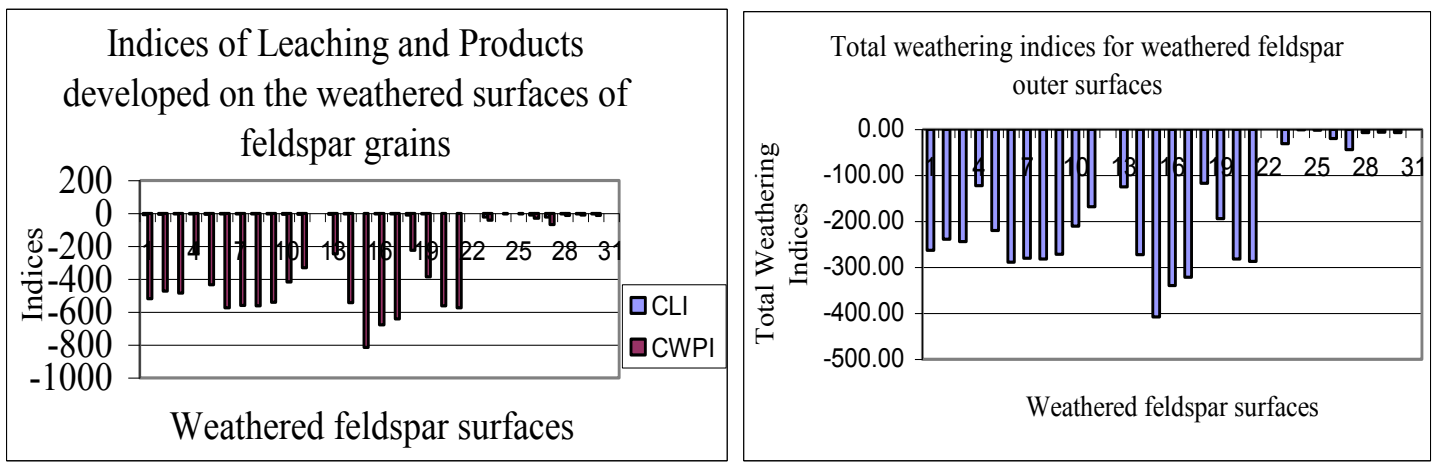

Fig. $2 a$ and $b$ show negative indices of chemical leaching and weathered products. They indicate removal of weathered products from the feldspar grains subjected to intensive weathering
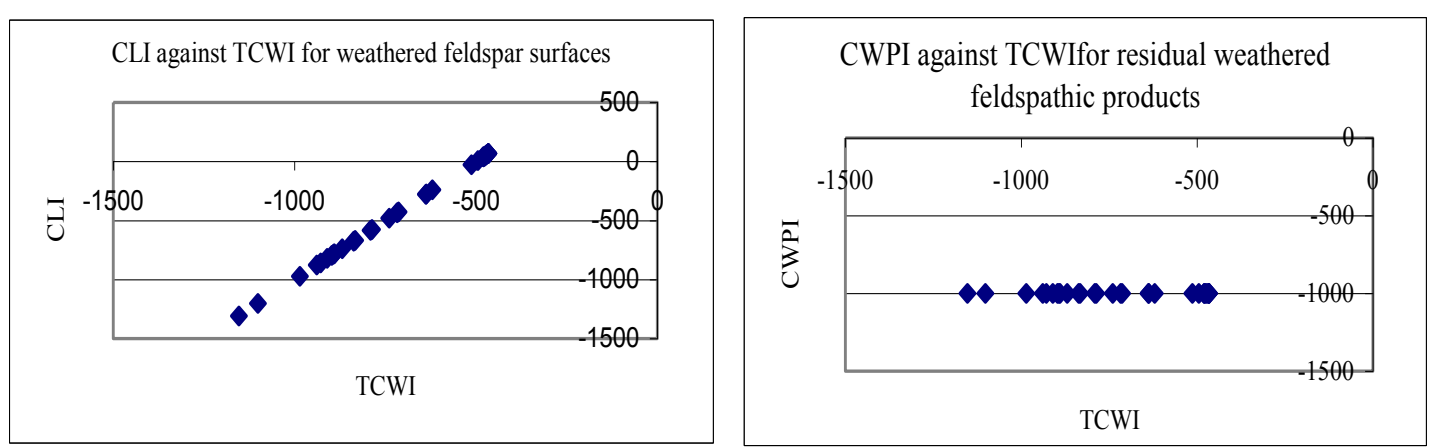

Fig $3 \mathrm{a}$ and $\mathrm{b}$ indicate distributions of Chemical Leaching Index, Chemical Weathering product index against Total Chemical Weathering index of in situ weathering of 3 grains of feldspar. These diagrams indicate that core portions of feldspar grains are extremely leached out and decayed with high degree of positive TCWI, CLI and CWPI indicating that they were well exposed to differential weathering.
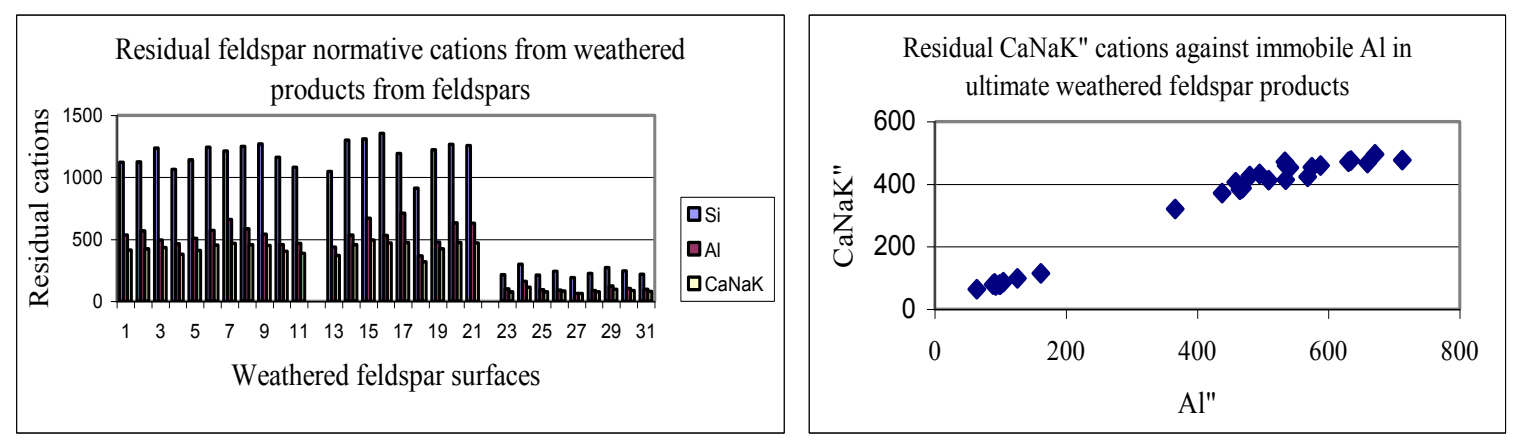

Fig. 4a shows Distributions of $\mathrm{Si}, \mathrm{Al}, \mathrm{Ca}+\mathrm{Na}+\mathrm{K}$ constituents in extrapolated normative feldspar constituents.

Large quantities of immobile $\mathrm{Al}$ ions are necessary to compensate the loss of $\mathrm{Al}$ ions leached out in grains 1 and 2 while limited cations are required for weathered materials in grain 3 are found. Fig. $4 \mathrm{~b}$ shows a linear trend for grains I \& II, with enrichments of carbonates as relicts of chemical leaching. The mobile elements of $\mathrm{Ca}+\mathrm{Na}+\mathrm{K}$ are transformed into insoluble carbonates. The trend for grain III (at the bottom portion with low Al" and CaNaK") differs from those of grain I and II. (with higher Al" and CaNaK"). The former trend shows enrichments of $\mathrm{Al}$ ions by precipitation of kaolinite in the shadow regions of weathering processes while the latter trends for grains I and II were due to direct facing and attack by leaching processes. These diagrams show weathered products are derived by weathering of feldspars.

\section{Discussion}

Feldspars comprise nearly two-thirds of in all granitic rocks. Leaching of feldspars dulls the polish of light reflecting surfaces and forms a thin pale grey clay film. Granite tends to weather from outer surface inward to interior portion in millions of years. The degree of weathering strongly determines the rock strength and durability. However, the rate of weathering is difficult to evaluate because of too many natural factors influence 
the natural weathering processes. Silicate minerals have tight crystal lattices with Si-O tetrahedra acting as the skeleton to which $\mathrm{Al}, \mathrm{Fe}$ and other $\mathrm{Ca}, \mathrm{Na}, \mathrm{K}, \mathrm{Mg}, \mathrm{Fe}$ cations are attached. The tightness of such lattices determines the case of separation from the almost inseparable $\mathrm{SiO}_{2}$ molecules. Leaching or dissolution can unlock and free some or all of these ions and fill the void spaces with water; as chemical weathering continues, clay and quartz grains remain in the material attached to the surface of the clay minerals. Na is readily concentrated in the soil. $\mathrm{H}^{+}$ions with their high charge tend to penetrate the mineral surfaces readily breaking down the silicate structures. The parent mineral breaks down with the release of cations whereby the silica in the rock may either retain its original atomic arrangement or enter the dispersed state. $\mathrm{CO}_{2}$ discharged water doubled the leached rates for $\mathrm{Ca}, \mathrm{Mg}, \mathrm{Na}$ and $\mathrm{K}$. Orthoclase or sericite is much more sensitive to $\mathrm{CO}_{2}$ charged waters than are other minerals. The naturally weathered surfaces of feldspars are rough, pitted and covered in inorganic and organic debris and reaction products. Leaching $3.5 \% \mathrm{NaCl}$ solution almost doubles the loss of ions and increases the loss of $\mathrm{Fe}$ by an alarming factor of [15]. Pink granites have notable amount of fluid inclusions of up to sizes of $15 \mu \mathrm{m}$ in feldspars and quartz. Such fluid inclusions have varying volume proportions and concentrations of brine solutions, sylvite $(\mathrm{KCl})$ and halite $(\mathrm{NaCl})$ daughter minerals. Breaking down of minerals containing these fluid inclusions during the weathering process and dissolution in rain water promotes weathering activities. Solubility of silica in rain water as a function of the temperature in the $\mathrm{pH}$ range between 2 and 8, further the solubility increases rapidly at $\mathrm{pH} 11$ and above, in alkaline state Smaller the grain size intensity of solubility increases.

These grains are enriched with orthoclase components. A crude zonal geochemical variation is seen around the feldspar grains analyzed both in longitudinal ( 7 or 5$)$ and horizontal directions (4). Though $4^{\text {th }}$ or $3^{\text {rd }}$ analyzes in the longitudinal direction is representing the composition of central portion and hence only two analyses were carried out on either side of the horizontal direction. From the cylindrical shape of the grain 1 , it is known that the central portion might be exposed to intensive weathering than the peripheral portions and it might be opened inner portion of the mineral by spheroidal weathering. However, the peripheral portions are situated close to micro cavities formed at the contact of the feldspar grain. The grains II and III are appeared to be broken pieces of feldspar grains exhibiting the crystal form of (010). Hence the central portions of these grains might be nucleus of the early formed minerals. The crystal growth of these minerals is controlled by crystal field stabilization theory. The early formed feldspar crystals are deposited over the crystal projections, edges and solid angles than in the flat faces. There exist compositional differences between the early formed feldspar minerals than the later formed minerals. Generally more anorthite / plagioclase molecules concentrate in the early formed feldspar at the core. Plagioclase grains are normally zoned with plagioclases of lower anorthite contents during the course of crystallization and differentiation from common parent magma. However, due to changes of kinetic processes due to upward movement during the course of crystallization from the magma oscillatory zonings might be formed. Reverse zoning i.e. presence of plagioclase layers with increasing anorthite content around the feldspar grains may be formed by swirling currents developed in the magma or by some metasomatic processes. Several different magmatic and metasomatic processes involved during the course of crystallization of feldspars often reveal their complex evolutionary trends. The compositional changes of feldspar grains during their growth should be adequately correlated with the compositional variations caused by weathering processes. During weathering geochemically mobile elements, such as silica, alkali and alkali-earth elements are easily leached from rocks, leaving the residual immobile elements of $\mathrm{Al}^{\mathrm{vi}}$ and $\mathrm{Fe}$ " to combine with feldspathic components from the atmosphere to form new minerals.

Some of the free silicon ions that existed during weathering of the rocks formed as clay minerals and the others moved away as colloid in a solution. Because of the low solubility of $\mathrm{Al}_{2} \mathrm{O}_{3}$, it tends to concentrate in residual weathering products rather than solutions. $\mathrm{CaO}$ and $\mathrm{Na}_{2} \mathrm{O}$ decrease quickly during the early stages of weathering as a result of the alteration of epidote and hornblende \pm plagioclase [16]. Some $\mathrm{Ca}$ and $\mathrm{Na}$ are probably fixed on the newly formed alteration products, such as in clays.

\section{Conclusions}

The present study shows that the three grains of feldspar analyzed from the granite patina collected at the Peruvudaiyaar Koil are subjected to alteration of kaolinite and carbonates in patches on the outer surfaces of the grains in different proportions. The grains 1 and 2 are extremely enriched with residual $\mathrm{Si}$ ions by dissolution and removal of $\mathrm{Al}$ by removal of kaolinite and precipitated insoluble carbonates of $\mathrm{Ca}, \mathrm{Na}$, and $\mathrm{K}$ by differential weathering with relicts of quartz by direct attack of differential weathering. The orientations of these two grains are directly exposed to the direction of weathering agents such as rainwater and atmosphere. On the other hand precipitation of kaolinite and carbonates took place due to different type of orientation of grain III exposed in the shadow regions associated with some cavities to the direction of differential weathering. The differential weathering, mainly by the attack of rain water during the course of the past one thousand years has induced significant weathering effects on the outer surface of feldspar grains. These variations are mainly due to their different sizes, shapes, and orientations of feldspar grains as well as their associations with adjoining 
micro-cavities, cleavage planes, micro fractures and their hydrophilic and hydrophobic characteristics of their outer surfaces. The significant chemical changes are incurred due to the impacts differential weathering processes which warrant for the need of adequate protection of the sculptures of temple by coating with weather proof paints.

\section{Acknowledgements}

The authors express their gratitude to Mrs. S. Shanthi, Scientist, Metallurgical Laboratory, Indian Institute of Technology, Madras, and Chennai-36 for carrying out microprobe analyses.

\section{References}

[1] George Mitchell, the Hindu Temple. Chicago: University of Chicago Press. 1988, 145-48.

[2] A.E. Blum. Feldspars in weathering, In: Feldspars and their reactions, ed., I. Parson, I. Kluwer, The Netherlands, 1994. 595-630

[3] M.J. Wilson, Weathering of the primary rock forming minerals: processes, products and rates, Clay. Miner, 39, 2004. 233-266.

[4] N. Schiavon, Kaolinization of granite in an urban environment, Environmental Geology, 52, 2, 2007, 399-407 (9)

[5] A. Rittmann, Stable Igneous Mineral Assemblages of Igneous Rocks, Elsevier, Amsterdam 1973

[6] W.A. Deer, R.A. Howie, and J. Zussman, An Introduction to the Rock Forming Minerals, $2^{\text {nd }}$ Edn, Parson Prentice Hall, London, 1992 p.696.

[7] T.F.W. Barth, Theoretical Petrology, J. Wiley, New York 1962.

[8] S. Ceryan, New chemical weathering indices for estimating the mechanical properties of rocks: A case study from Kurtun Granodiorite, NE Turkey, Turkish J. Earth Sci. 17, 2007, 187-207

[9] Parker, An index of weathering for silicate rocks, Geological Magazine, 107, 1970, $501-04$.

[10] A.PW. Hodder, Thermodynamic interpretation of weathering indices and its application to engineering properties of rocks, Engineering Geology, 20,1984, 241-51

[11] M.S. Kim, H.D. Park, The relationship between physical and chemical weathering indices of granites around Seoul, Korea. Bulletin of Engineering Geology and the Environment 62, 2003 207-12.

[12] A.Putnis, Mineralogical replacement reactions from macroscopic observations to microscopic mechanisms, Mineralogical Magazine, 66, 2002 689-708

[13] B. Fitzner,,K. Heinrich, In Understanding and managing stone decay. Prikryl, R., Viles, H.A. (Eds) The Karolinum Press, Prague, 2002 11-56.

[14] R.A. Berner, and O.R. Holdren, Mechanism of feldspar weathering: Some observational evidence, Geology, 5 (6) 1977, 369-72

[15] E.M. Winkler, Stone in Architecture Properties Durability Springer -Technology and Engineering $1994,313$.

[16] F.C. Loughnan, Chemical weathering of Silicate Minerals, Elsevier, Amsterdam 1969 